\title{
Production and stability of low amount fraction of formaldehyde in hydrogen gas standards
}

Thomas Bacquart $^{* a}$, Mark Perkins ${ }^{\mathrm{b}}$, Valerio Ferracci ${ }^{\mathrm{a},}{ }^{\dagger}$, Nicholas A Martin ${ }^{\mathrm{a}}$, Kate Resner $^{\text {a, Michael K.M. Ward }}{ }^{\text {a }}$, Nathan Cassidy ${ }^{\text {a }}$, Joshua B Hook ${ }^{\text {a }}$, Paul J. Brewer ${ }^{\text {a }}$, John T.S. Irvine ${ }^{c}$, Paul A. Connorc, Arul Murugan ${ }^{a}$

Affiliation:

a. Chemical, Medical, Environmental Science Department, National Physical Laboratory, Hampton Road, Teddington, Middlesex, TW11 0LW, UK

b: Anatune Ltd, Unit 4, Wellbrook Court, Girton Road, Cambridge, CB3 0NA, UK

': School of Chemistry, University of St Andrews, Fife, KY16 9ST, UK

${ }^{\dagger}$ now at the Centre for Atmospheric Informatics and Emissions Technology, Cranfield University, College Road, MK43 0AL, UK

Corresponding author:

E-mail: Thomas.bacquart@npl.co.uk

Tel: +44 (0)20 89436652

Keywords:

Formaldehyde, hydrogen, ISO14687, gas analysis, degradation products, "gas standard" 


\begin{abstract}
Formaldehyde is an intermediate of the steam methane reforming process for hydrogen production. According to International Standard ISO 14687-2 the amount fraction level of formaldehyde present in hydrogen supplied to fuel cell electric vehicles (FCEV) must not exceed $10 \mathrm{nmol} \mathrm{mol}^{-1}$. The development of formaldehyde standards in hydrogen is crucial to validate the analytical results and ensure measurement reliability for the FCEV industry. NPL demonstrated that these standards can be gravimetrically prepared and validated at $10 \mu \mathrm{mol} \mathrm{mol}^{-1}$ with a shelf-life of 8 weeks (stability uncertainty $<10 \% ; k=1$ ), but that formaldehyde degrades into methanol and dimethoxymethane, as measured by FTIR, GC-MS and SIFT-MS. The degradation kinetics is more rapid than predicted by thermodynamics, this may be due to the internal gas cylinder surface acting as a catalyst. The identification of by-products (methanol and dimethoxymethane) requires further investigation to establish any potential undesirable impacts to the FCEV.
\end{abstract}

\title{
Introduction
}

The demand for hydrogen fuel cell vehicles is growing across Europe and several countries worldwide have initiated national policies to rapidly introduce hydrogen technologies to the market over the next few decades. In the UK it is expected that there could be 1.6 million fuel cell vehicles on the road by 2030 supported by 1,100 hydrogen refuelling stations [1]. Hydrogen fuel cell vehicles have strict requirements in term of hydrogen purity [2]. Formaldehyde is an intermediate of the steam methane reforming process, which is currently the prevalent method for producing hydrogen. Without appropriate purification steps downstream of the process formaldehyde may end up in the hydrogen product. Formaldehyde is one of the 13 gaseous impurities that has to be monitored according to the international standard ISO 14687-2 [2]: if present in the hydrogen fuel it will reduce the lifetime of fuel cells [3]. It is therefore crucial for users and producers that formaldehyde in hydrogen is measured accurately.

One potential barrier that could prevent the uptake of hydrogen technologies in Europe is European Directive 2014/94/EU on the deployment of an alternative fuels infrastructure [3] which sets out that "The hydrogen purity dispensed by hydrogen refuelling points shall comply with the technical specifications included in the ISO 14687 2 standard." According to this Directive it will be the responsibility of the hydrogen supplier or system integrator to obtain the evidence that proves that their hydrogen is of suitable purity to be provided to a fuel cell vehicle. This involves reliable purity testing to show that none of the threshold limits for the 14 impurities specified in ISO 14687-2 [2] are exceeded. The maximum limit for the amount fraction of formaldehyde is set at $10 \mathrm{nmol} \mathrm{mol}^{-1}$, which represents an analytical challenge.

A recent literature review by Murugan and Brown [4] compiled all known gas analysis methods for performing purity analysis of fuel cell hydrogen. According to this review, a variety of analysers have been identified for performing measurements of formaldehyde in hydrogen such as cavity ring-down spectroscopy (CRDS) [5], gas chromatography-mass spectrometry (GC-MS) [6], chromatography with methaniser and flame ionisation detection (GC-methaniser-FID) [7] and Fourier-transform infrared spectroscopy (FTIR) [8]. In addition, other techniques have already demonstrated their capability to measure formaldehyde in air, as in the case of differential optical absorption spectroscopy (DOAS) [9], colorimetric method [10] and tuneable diode-laser absorption spectroscopy (TDLAS) [11]. Recently proton transfer reaction mass spectrometry (PTR-MS) [12] and selected-ion-flow-tube mass spectrometry (SIFT-MS) [13] were used to measure formaldehyde in air. SIFT-MS was considered a promising technique to detect formaldehyde in hydrogen due to the sufficiently high detection sensitivity and its capability to work with a hydrogen gas matrix.

Recent inter-laboratory comparison studies from Hak et al. [14] and Wisthaler et al. [15] observed disagreements in the analysis of formaldehyde samples in air by different techniques. Panda et al. [16] attributed this disagreement to the difficulties encountered in the calibration of the instruments and emphasised the need for reliable and traceable formaldehyde gas standards. However preparing a formaldehyde gas standard is challenging due to the reactivity of the molecule itself and the difficulty to find high purity formaldehyde [16-17]. In general, Primary Reference Materials (PRMs) are prepared from the pure gas components, but formaldehyde is not easily available in pure form as it can polymerise into more stable forms such as trioxane or paraformaldehyde at room temperature [16-18]. A variety of methods have been used to generate calibrated mixtures of formaldehyde including permeation devices, diffusion cells, reaction vessels and static gas cells [17]. There are also several alternative methods, detailed in the literature, that usually require a reaction between stable compounds to form formaldehyde. Examples of these include the reaction between ethane and ozone or depolymerisation of paraformaldehyde or alpha-polyoxymethylene [16]. NPL has developed a method for producing $10 \mu \mathrm{mol} \mathrm{mol}^{-1}$ formaldehyde in nitrogen PRMs by heating trioxane to high temperatures $\left(230^{\circ} \mathrm{C}\right)$ [18]. At this temperature the solid trioxane decomposes into gaseous formaldehyde which then diffuses into an evacuated gas cylinder; the required matrix gas is then added directly into the cylinder. The key advantage of this method is that the amount of formaldehyde added to the gas cylinder can be accurately determined through a measurement of the mass loss of 
the trioxane and, unlike dynamic methods, no large flows of diluent gas are required (as is the case with permeation tubes and diffusion cells). Stability tests performed on the PRMs indicate that a loss between 1.6 and $0.07 \mathrm{nmol} \mathrm{mol}^{-1}$ per day could be achieved [18], implying that for a mixture of $10 \mu \mathrm{mol} \mathrm{mol}^{-1}$ formaldehyde in nitrogen a loss of 26 to $576 \mathrm{nmol} \mathrm{mol}^{-1}$ would occur over a year. However the stability of mixtures of formaldehyde in nitrogen and of those in hydrogen are expected to be different; for instance, the reaction of formaldehyde with hydrogen to form methanol is the simple addition of hydrogen across the $\mathrm{C}=\mathrm{O}$ double bond in formaldehyde. This reaction has been studied in the gas phase, as it is the final step in the formation of methanol from the reaction of hydrogen with carbon monoxide or carbon dioxide. These studies [19,20,21] are based on high concentrations of hydrogen, carbon monoxide/carbon dioxide and formaldehyde; however the energetics of the system, which control the thermodynamics and kinetics of the reaction, are similar over all ranges of amount fraction.

It is therefore the purpose of this paper to describe the production of formaldehyde in hydrogen PRMs using the approach of Brewer et al. [18]. This paper also investigates the stability of these PRMs to underpin traceable purity measurements for quality assurance of fuel cell hydrogen. These mixtures are validated using four analytical methods (GC-MS with pre-concentrator, SIFT-MS, FTIR and GC-methaniser-FID) that have been developed as part of this work.

\section{Materials and methods}

\subsection{Preparation of formaldehyde gas standards}

Static reference standards of formaldehyde were prepared from diffusion of the trioxane sublimate followed by its thermal conversion, as detailed in the work by Brewer et al. [18]. A pellet of 1,3,5-trioxane (purity: $99.5 \%$, Acros Organics, UK; $4-5 \mathrm{~mm}$ in length and approximately $0.1 \mathrm{~g}$ in mass) was prepared and added to a transfer loop, consisting of a piece of $1 / 8$ inch diameter tubing with Swagelok fittings on each end. A granule of phosphorous pentoxide $\left(\mathrm{P}_{4} \mathrm{O}_{10}\right.$, Sigma Aldrich Company Ltd, UK) was also placed in the transfer loop, which was then connected to a vacuum pump via a three-way valve. The transfer loop and the valve were evacuated to a pressure of $4 \times 10^{-3} \mathrm{mbar}$ to ensure no contaminants or air were present in the system or on the surface of the trioxane pellet. The evacuated transfer loop and valve were then weighed on a balance (Sartorius Research, UK). Following the weighing, a converter unit was connected to the transfer loop via the three-way valve. The converter, consisting of a long piece of $1 / 16$ inch Silconert-treated tubing coiled within a thermally insulating jacket, was set to the optimum conversion temperature of $(230 \pm 1){ }^{\circ} \mathrm{C}$. The output of the converter was connected to a minimised dead volume (MDV) valve developed at NPL on an evacuated cylinder (10 L SPECTRA-SEAL $®$ cylinder, BOC, UK). The connection from the cylinder to the transfer loop (including the MDV valve and the converter) was evacuated to a pressure of $3 \times 10^{-5} \mathrm{mbar}$. The transfer loop was then opened to the converter, followed by the opening of the cylinder valve: this enabled the transfer of trioxane via the converter to the cylinder. In order to prepare a mixture containing $10 \mu \mathrm{mol} \mathrm{mol}^{-1}$ formaldehyde in hydrogen, the transfer loop was left open for approximately 3 hours in order to transfer approximately $10 \mathrm{mg}$ of formaldehyde into the cylinder. This was calculated from the vapour pressure of trioxane at $20^{\circ} \mathrm{C}$ [18]. When the transfer was complete, the three-way valve on the transfer loop was shut but the cylinder valve was left open for an additional two minutes to allow the transfer of any residual formaldehyde in the capillary tube within the converter into the cylinder. After this, the cylinder valve was closed. The transfer loop and valve were disconnected from the converter and weighed: the mass difference between postand pre-transfer corresponded to the mass of formaldehyde added to the cylinder. Prior to filling with pure hydrogen, the gas cylinder was weighed on a top-pan balance (Mettler Toledo KA30-3/P, UK). To prevent repolymerisation of formaldehyde, the cylinder was filled with 10 bar of hydrogen just after the transfer of formaldehyde in the $10 \mathrm{~L}$ cylinder and then rolled for 20 minutes. After rolling the cylinder, the remaining 90 bar of hydrogen were added. Then the cylinder was weighed and rolled for a further two hours. A list of the mixtures prepared for this study is shown in Table 1. The reference amount fractions quoted were calculated from the masses of formaldehyde and hydrogen introduced in the cylinder. The purity of formaldehyde in the mixture was assessed by FTIR and GC-MS with a preconcentrator. 
Table 1. NPL PRMs of formaldehyde amount fraction in hydrogen and associated uncertainty.

\begin{tabular}{|c|c|c|c|}
\hline Mixture & $\begin{array}{c}\text { Formaldehyde amount fraction and uncertainty }(k=1) \\
{\left[\mu \mathrm{mol} \mathrm{mol}^{-1}\right]}\end{array}$ & Matrix & $\begin{array}{c}\text { Date of } \\
\text { preparation }\end{array}$ \\
\hline A & $12.85 \pm 0.12$ & nitrogen & $16 / 10 / 2013$ \\
\hline B & $9.88 \pm 0.15$ & hydrogen & $24 / 07 / 2015$ \\
\hline C & $10.00 \pm 0.12$ & hydrogen & $24 / 07 / 2015$ \\
\hline D & $9.88 \pm 0.12$ & hydrogen & $07 / 04 / 2016$ \\
\hline E & $11.11 \pm 0.28$ & hydrogen & $17 / 01 / 2017$ \\
\hline
\end{tabular}

\subsection{Stability study of formaldehyde in hydrogen}

The stability of mixtures B and C (Table 1) was monitored over 1.5 years. The mixtures were analysed on the day of production and then on days $3,4,5,10,18,25,40,60,83,105,139,165,203,396$ and 545 after preparation using a GC-methaniser-FID set-up. The measurements were made in comparison to mixture A, which was prepared in nitrogen and used as a stable reference [18]. Mixture D was analysed on the day of production, and then 4 and 8 months later using the same GC-methaniser-FID instrument. Mixture E was measured on the day of production at the same time as mixtures $\mathrm{A}, \mathrm{B}, \mathrm{C}$ and $\mathrm{D}$ to perform an isochronous stability analysis aimed at minimising the impact of day-to-day analysis variation: for this particular measurement, all mixtures prepared in hydrogen (mixtures B, C, D and E) were analysed under repeatable condition against the reference standard (mixture A). This allowed any variations between the mixtures in hydrogen and the standard caused by instability to be established.

\subsection{Analytical methods}

\subsubsection{Fourier-transform infrared (FTIR) spectroscopy}

FTIR spectroscopic measurements of standards prepared at $10 \mu \mathrm{mol} \mathrm{mol}^{-1}$ of formaldehyde in hydrogen were made on a benchtop FTIR spectrometer (Nicolet 6700, Thermo Fisher Scientific, UK) equipped with $\mathrm{N}_{2}$ purged multi-range optics, a KBr beam splitter and a liquid nitrogen cooled MCT-A detector. The spectrometer was fitted with a "White" type gas cell (Cyclone C5, Specac, UK), nominal path length: $8 \mathrm{~m}$ and volume $=2 \mathrm{~L}$, equipped with a borosilicate glass body and $\mathrm{KBr}$ windows. Absorption spectra of the formaldehyde standards and the background single beam spectra of a pure hydrogen gas (Hydrogen BIP ${ }^{\circledR}+$, Air Products, UK) were made at a temperature of $29{ }^{\circ} \mathrm{C}$, pressure of $1050 \mathrm{mbar}$ with a sample flow rate of $0.5 \mathrm{~L} \mathrm{~min}^{-1}$. The instrumental spectral resolution was $0.5 \mathrm{~cm}^{-1}$ and the spectral window ranged from 4000 to $640 \mathrm{~cm}^{-1}$.

\subsubsection{Gas chromatography with methaniser and flame ionisation detector (GC-methaniser-FID)}

A GC-methaniser-FID (Peak Laboratories, US) instrument was used to measure formaldehyde in hydrogen. The measurement routine involved a Hayesep ${ }^{\circledR}$ D packed column (Peak Laboratories, US) to separate the formaldehyde from other compounds. In order to ensure fast elution of the formaldehyde component, the oven temperature was set at $170{ }^{\circ} \mathrm{C}$. Formaldehyde was converted into methane using a methaniser set at $270{ }^{\circ} \mathrm{C}$, which was then detected using FID. The instrument was calibrated using a standard of formaldehyde in nitrogen (mixture A; National Physical Laboratory, UK). The analyses were performed under the same conditions for the duration of the study, with sample flow rates of $30 \mathrm{~mL} \mathrm{~min}^{-1}$ and the sample loop size of $5 \mathrm{~mL}$. Prior to each run, the injection line was thoroughly purged seven times with high flow (above $100 \mathrm{~mL} \mathrm{~min}^{-1}$ ) to remove any trace of contaminants from the previous analysis and any traces of air.

\subsubsection{Gas chromatography with mass spectrometry (GC-MS) and preconcentrator}

The sampling system employed to analyse the mixtures consisted of an Entech 7200 preconcentrator (Entech Instruments Inc., US) coupled to an Agilent 7890A GC with 5975C inert XL mass spectrometry detector (Agilent, US). This instrument was specially configured to detect dry or humidified samples of volatile organic compounds (VOCs) at amount fractions in the $\mathrm{nmol} \mathrm{mol} \mathrm{m}^{-1}$ to $\mu \mathrm{mol} \mathrm{mol} \mathrm{mog}^{-1}$ regime.

Aliquots of gas $(100 \mathrm{~mL})$ from each gas mixture were introduced through a silanised stainless steel line into the preconcentrator, which contained three traps which were cryogenically cooled with liquid nitrogen to remove water vapour and permanent gases. Initially Trap 1 was cooled to $-40{ }^{\circ} \mathrm{C}$ to collect the sample, and then was heated to $10^{\circ} \mathrm{C}$. The gas sample was then transferred into trap 2, which contained the sorbent Tenax, maintained at -30 ${ }^{\circ} \mathrm{C}$. Trap 2 was then heated to $180{ }^{\circ} \mathrm{C}$ and the sample was then transferred to trap 3 . This trap was cooled to -160 ${ }^{\circ} \mathrm{C}$ and then heated to $60{ }^{\circ} \mathrm{C}$, to introduce the sample into the GC. The analysis of the formaldehyde in nitrogen and formaldehyde in hydrogen samples was carried out in the GC with a column (Agilent $\mathrm{J} \& \mathrm{~W}$ ) containing a stationary phase of DB-5MS $(60 \mathrm{~m} \times 0.320 \mathrm{~mm} \times 1.00 \mu \mathrm{m})$, which could operate in the oven temperature range - 
$60^{\circ} \mathrm{C}$ to $325^{\circ} \mathrm{C}$. In the $\mathrm{GC}$ method the oven was initially maintained at $35^{\circ} \mathrm{C}$ for 5 minutes, and then temperature ramped to $85{ }^{\circ} \mathrm{C}$ at $10{ }^{\circ} \mathrm{C} \mathrm{min}-1$ for optimum separation of formaldehyde from other potential impurities. An important advantage of this method over direct injection into a GC was that the chromatographic retention times of the various components in the sample were not affected by matrix effects since the output of the preconcentrator in the GC contained little of the hydrogen diluent. The mass spectrometer was useful in conclusively identifying the parent formaldehyde and the presence of any impurities or decomposition products.

\subsection{4. $\quad$ SIFT-MS}

Analysis of the formaldehyde gas mixtures was carried out on a Syft Technolgies' Voice 200ultra SIFT-MS (Syft Technologies, NZ) directly from the gas cylinders. The sample was introduced to the instrument via a heated transfer line at $120{ }^{\circ} \mathrm{C}$, using a flow passed configuration. The SIFT-MS instrument passively sampled at

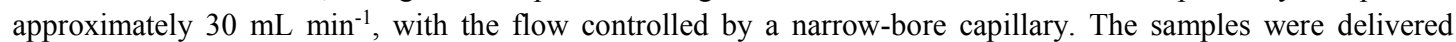
directly from the gas cylinder to the instrument using $1 / 8$ inch stainless steel tubing attached to the transfer line via a T-piece union. The flow from the cylinder was kept above $50 \mathrm{~mL} \mathrm{~min}^{-1}$, with the instrument sampling at the required rate, with any excess sample flow passing across the T-piece to vent. Full mass scans were run for the three positive reagent ions $-\mathrm{H}_{3} \mathrm{O}^{+}, \mathrm{NO}^{+}$and $\mathrm{O}_{2}{ }^{+}-$from $m / z 15$ to $150 \mathrm{Da} \mathrm{e}^{-1}$. Concentrations were calculated from the full mass scan data, using the reaction rate constants $(k)$ available in the instrument library. The validity of these reaction rates have not been confirmed for compounds in hydrogen, therefore the results should be taken as indicative only.

\subsubsection{Gas chromatography with pulse discharge helium ionisation detector (GC-PDHID)}

A custom-made Agilent 7890A GC-PDHID (AC analytical controls BV, NL) performed accurate measurements of carbon monoxide in mixtures A, B and C. The GC was equipped with a Molsieve 5A PLOT column $(30 \mathrm{~m} \times 0.53$ $\mathrm{mm} \times 50 \mu \mathrm{m}$, Restek, UK) and used helium as carrier gas. The sample loop was $1 \mathrm{~mL}$ in volume and the sample flow rate was set at $(30 \pm 2) \mathrm{mL} \mathrm{min}^{-1}$. The detector used was a pulse discharge helium ionisation detector from VICI (Restek, UK). The carbon monoxide retention time for the method used was $8 \mathrm{~min}$. The instrument was calibrated using gravimetric standards of 0.1 and $1 \mu \mathrm{mol} / \mathrm{mol}$ carbon monoxide in hydrogen produced and validated by the National Physical Laboratory (Teddington, UK). Prior to each run, the injection line was thoroughly purged seven times with high flow (above $100 \mathrm{~mL} \mathrm{~min}^{-1}$ ) to remove any trace of contaminants from the previous analysis and any traces of air.

\subsection{Data treatment and evaluation}

\section{SIFT-MS quantification}

Whilst SIFT-MS is inherently quantitative, the quantitation relies on accurate values for the ion-molecule reaction rate constants $\left(k_{r}\right)$ for the reactions taking place in the flow tube. There are numerous literature sources for this data $[22,26]$, however there is very limited data on reaction rate constants in hydrogen gas matrices. The $k_{r}$-values used in the calculations in this paper are derived from analytes in either helium, nitrogen or air and consequently may not be correct. For this reason, the SIFT-MS results should be taken as indicative only.

Three $k_{r}$-values were used in this study: $k_{r, H e}=3.4 \times 10^{-9} \mathrm{~cm}^{3} \mathrm{~s}^{-1}$ from Helium reaction rate ' $k_{r}$ ' coefficients, $k_{r, N 2}=$ $1.16 \times 10^{-9} \mathrm{~cm}^{3} \mathrm{~s}^{-1}$ derived from SIFT analysis of formaldehyde in nitrogen NPL gas standard (Reference value: $12.2 \mu \mathrm{mol} \mathrm{mol}^{-1}$ in nitrogen matrix) and a revised value of the $k_{r, N 2 c o r r}$ coefficient derived from SIFT analysis of formaldehyde in nitrogen NPL gas standard (decay rate: $1.6 \mathrm{nmol} \mathrm{day}^{-1}$ ) to consider potential degradation of the standard over time $k_{r, N 2 \mathrm{corr}}=1.35 \times 10^{-9} \mathrm{~cm}^{3} \mathrm{~s}^{-1}$.

\section{Normalisation}

As the response of the detectors coupled with gas chromatography can exhibit significant day-to-day variations, a data normalisation routine was applied to the stability study of formaldehyde in hydrogen by GC-methaniser-FID in order to limit the uncertainty or bias introduced by performing repeat measurements over long periods of time. The normalisation procedure was based on the assumption that mixture A (formaldehyde in nitrogen) was stable over the whole duration of the study. Mixture A was therefore used as the reference standard and the following equation was applied:

$$
x_{\text {norm }, \mathrm{y}, \mathrm{t}}=\frac{x_{y, t}}{x_{r e f, t}}
$$

$x_{\text {norm,y,t }}$ normalised formaldehyde amount fraction $y$ at time $t$

$x_{\mathrm{y}, \mathrm{t}} \quad$ certified formaldehyde amount fraction for mixture $y$ at time $t$

$x r e f, \mathrm{t}$ reference formaldehyde amount fraction for mixture A at time $t$ 
The uncertainty reported was the combination of the measurement uncertainties of the sample and of the reference standard (mixture A), each estimated as the relative standard deviation of more than three measurements.

\section{Stability}

Due to the intrinsic variation of measurement results, no study can rule out the degradation of materials completely, even in the absence of statistically significant trends. It is therefore necessary to quantify the potential degradation that could be hidden by the method repeatability, i.e. to estimate the uncertainty of stability. This means, even under ideal conditions, the outcome of a stability study can only be "degradation is $0 \pm \mathrm{x} \%$ per unit time".

Uncertainties of stability during dispatch and storage were estimated as described in [23] for each parameter. For this approach, the uncertainty of the linear regression line with a slope of zero is calculated. The uncertainty contribution $u_{\text {sts }}$ and $u_{\text {lts }}$ are calculated as the product of the chosen transport time/shelf life and the uncertainty of the regression lines as:

$$
u_{\mathrm{lts}, \mathrm{rel}}=\frac{R S D}{\sqrt{\sum\left(x_{i}-\bar{x}\right)^{2}}} \cdot t_{\mathrm{sl}} \quad \text { Equation } 2
$$

$R S D \quad$ relative standard deviation of all results of the stability study

$x_{\mathrm{i}} \quad$ result at time point $i$

$x \quad$ mean results for all time points

$t_{\mathrm{sl}} \quad$ chosen shelf life $\left(8\right.$ weeks at $\left.18^{\circ} \mathrm{C}\right)$

The following uncertainties were estimated:

- $\quad u_{\mathrm{lts}, \mathrm{rel}}$, the stability during storage. This uncertainty contribution was estimated from the $(18 \pm 2)^{\circ} \mathrm{C}$ study. The uncertainty contribution describes the possible degradation during 8 weeks storage at $18^{\circ} \mathrm{C}$.

\section{Results and discussion}

\subsection{Validation of formaldehyde in hydrogen gas mixtures}

The gas mixtures produced at $10 \mu \mathrm{mol} \mathrm{mol}{ }^{-1}$ of formaldehyde in hydrogen were validated against a standard of formaldehyde in nitrogen (mixture A). The relative difference between the gravimetric formaldehyde amount fraction and the value obtained from the GC-methaniser-FID measurements was below $9 \%$. This difference may be due to the analytical method, or to the difference in matrix between the samples and the standard, or to the fast degradation of formaldehyde in hydrogen (Figure 1). FTIR and GC-MS were used to assess the presence of contaminants or by-products in the freshly prepared mixtures. As shown in Figures 2 and 3, the analysis support the fact that only formaldehyde was present in mixtures $\mathrm{B}$ and $\mathrm{C}$ on the day of production.

\subsection{Stability of formaldehyde in hydrogen}

\subsubsection{Evolution of formaldehyde amount fraction in hydrogen over time}

The evolution of the formaldehyde amount fraction in hydrogen was followed over time using the GC-methaniserFID technique. As described above, this relied on the assumption that the standard in nitrogen (mixture A) was completely stable during testing. The stability of mixture A was assessed by CRDS against a dynamic standard generated by diffusion [18]. The amount fraction of formaldehyde in nitrogen was considered to be stable (decay rate: $1.6 \mathrm{nmol} \mathrm{day}^{-1}$ ) within measurement uncertainty over the time of this study.

Figure 1 shows the normalised formaldehyde amount fraction in mixtures B and C over the timescale of this study. The first observation is the clear decrease in formaldehyde amount fraction: this appears reasonably linear for the first 300 days, only for the formaldehyde amount fraction to stabilise after this period. 


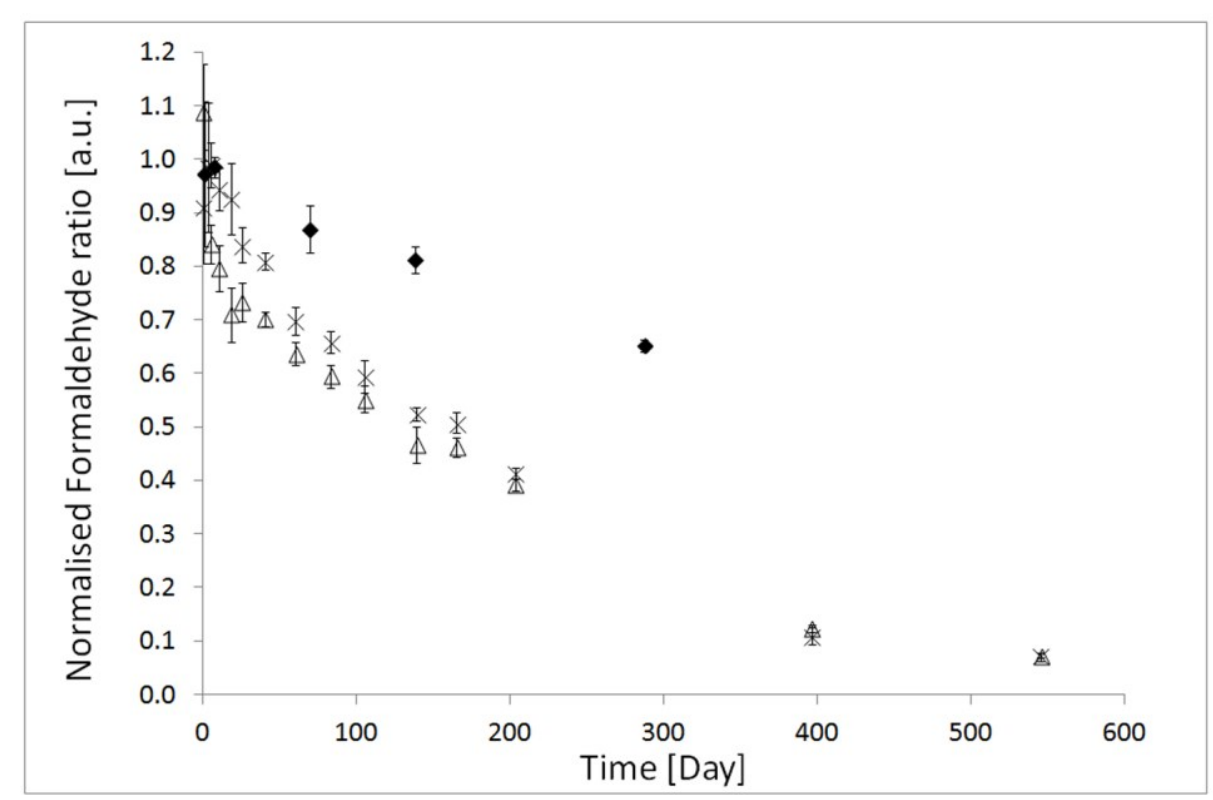

Figure 1. Normalised formaldehyde ratio of mixture B (symbol: $\mathrm{x}$ ), $\mathrm{C}$ (symbol: $\Delta$ ) and D (symbol: $\downarrow$ ) over time in days. Uncertainty is reported with $k=1$.

In order to certify gas mixtures, it is important to determine the uncertainty of the stability as defined in ISO Guide 34 [24]. For this reason and to minimise the impact of day-to-day variations, an isochronous study was performed. Standards prepared on different dates (in week 0, 56 and 78 since the beginning of the study) were analysed under repeatable conditions to observe deviations from the nominal amount fraction due to instability. For the isochronous study for formaldehyde, the time 0 (corresponding to mixture E), 56 (corresponding to mixture D) and 78 weeks (corresponding to mixture B) were evaluated. The slope of the linear regression was significant at the $95 \%$ confidence level. No outliers were observed using Grubb's test at the 95 and $99 \%$ confidence levels. For a given shelf life of 6 weeks, the relative stability uncertainty was estimated at $6.3 \%(k=1)$ including the degradation uncertainty. For a given shelf life of 8 weeks, the relative stability uncertainty was estimated at $8.4 \%(k=1)$ including the degradation uncertainty.

To evaluate the difference between an isochronous and a non-isochronous study, the normalised results of mixture B were used considering the following time points $(0,3.6,8.6,15,23.6,29,56$ and 78 weeks). The slope of the linear regression was significant at the $95 \%$ confidence level and no outliers were observed using Grubb's test at the 95 and $99 \%$ confidence levels. For a given shelf life of 6 weeks, the relative stability uncertainty was estimated to $7.1 \%(k=1)$ including the degradation uncertainty. For a given shelf life of 8 weeks, the relative stability uncertainty was estimated to be $9.5 \%(k=1)$ including the degradation uncertainty.

Regarding a shelf life of 8 weeks, the stability uncertainties obtained using the isochronous and non-isochronous analyses are in good agreement. For a formaldehyde standard in hydrogen, following the preparation procedure described in this study, it is recommended to use a stability uncertainty of $9.5 \%$ for a shelf life of 8 weeks.

The degradation rate seems to be different between mixture D and mixture B and C (Fig 1). Cylinders B and C were purchased from the same batch, whilst cylinder D came from a different batch (purchased one year later). Cylinders batch effect could not be ruled out as mixture D appeared more stable than mixtures B and C, indicating that further investigations are required.

\subsubsection{Determination of decomposition products}

Following the observation of decreasing formaldehyde amount fraction in a hydrogen matrix, three techniques were used on mixtures $\mathrm{B}$ and $\mathrm{C}$ to identify the formaldehyde degradation products for over 1 year from preparation.

Fourier-transform infrared (FTIR)

The FTIR spectroscopic technique was used to identify the compounds present in the mixture. The first objective was to confirm the purity of formaldehyde. After preparation of the formaldehyde in hydrogen gas standard, the FTIR spectra (Figure 2A) clearly matched the reference spectra from the Pacific Northwestern National Laboratory database (PNNL) [25]. The presence of the by-products dimethoxymethane or methanol were absent 


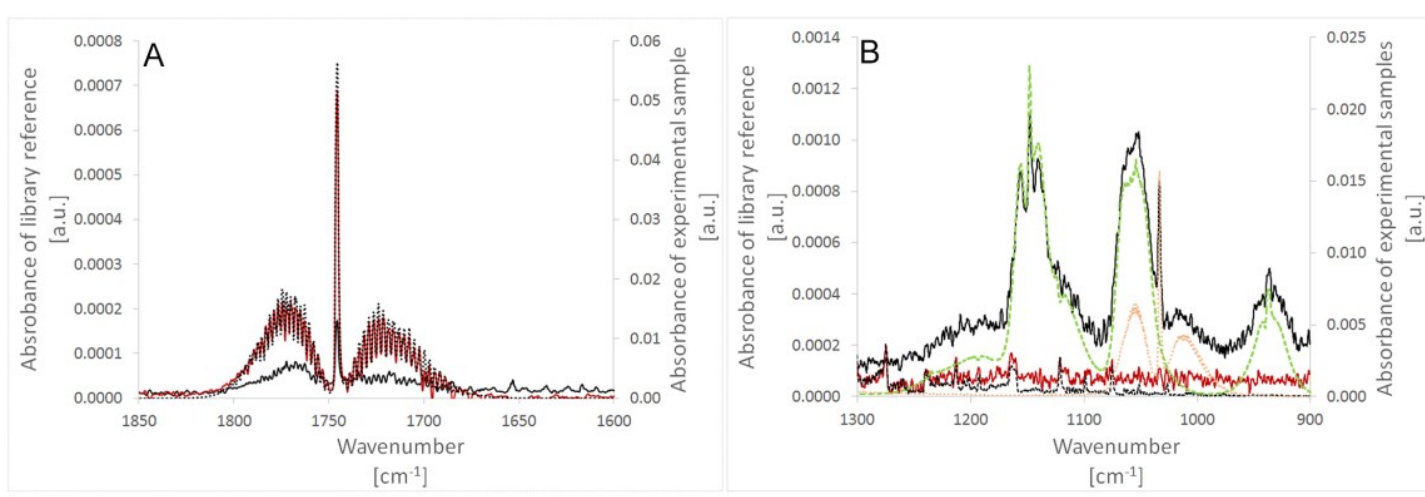

Figure 2. FTIR spectra of a formaldehyde in hydrogen standard after different storage times, held at ambient temperature. Figure 2A presents the FTIR spectra in wavelength area $1300-900 \mathrm{~cm}^{-1}$. This spectral region presents the characteristic absorptions from the $\mathrm{C}-\mathrm{O}$ bond in the methanol and dimethoxymethane fingerprint. Figure 2B presents FTIR spectra in wavelength area $1850-1600 \mathrm{~cm}^{-1}$. This spectra region presents the carbonyl stretch of formaldehyde. The red line correspond to formaldehyde in hydrogen after 1 day of production. The solid black line correspond to formaldehyde in hydrogen after 1 year. The grey dotted line corresponds to the formaldehyde reference spectrum; the green dotted line to the dimethoxymethane reference spectrum and the yellow dotted line to the methanol reference spectrum. All reference spectra are taken from the PNNL database

(Figure 2B). Comparison of the initial FTIR spectra of the mixtures with those taken more than one year later shows that formaldehyde has degraded with time as shown by the decrease in the principal absorption bands between $1810-1690 \mathrm{~cm}^{-1}$ (Figure 2). Furthermore the appearance of new absorption features at $1300-900 \mathrm{~cm}^{-1}$ implies the presence of new species that were not present when the standards were initially prepared, supporting the idea of formaldehyde undergoing reactions under the reducing atmosphere within the hydrogen cylinder.

By referring to library spectra from the PNNL database [25], the presence of methanol and dimethoxymethane can be identified from the convoluted absorption bands around $1300-900 \mathrm{~cm}^{-1}$ (Figure 2A) and $3100-2500 \mathrm{~cm}^{-1}$. The emergence of these species is the likely result of the reduction of the carbonyl bond within formaldehyde. The decrease of formaldehyde amount fraction over time (shown in Figure 2B) is correlated to appearance of methanol and dimethoxymethane, after one year of storage.

\section{SIFT-MS}

The SIFT-MS technique was also used to identify the by-products of the formaldehyde degradation in hydrogen gas. The full mass scans were run for the three positive reagent ions $-\mathrm{H}_{3} \mathrm{O}^{+}, \mathrm{NO}^{+}$and $\mathrm{O}_{2}{ }^{+}-$from $m / z 15$ to $150 \mathrm{Da}$ $\mathrm{e}^{-1}$ for formaldehyde in hydrogen standard aged 3 months (E) and 1.5 years (C) (Figure 3). The mass spectra using $\mathrm{H}_{3} \mathrm{O}^{+}$clearly showed a strong signal for $\mathrm{m} / \mathrm{z} 31\left(\mathrm{CH}_{2} \mathrm{OH}^{+}\right)$[22]. The mass spectra of the standard $\mathrm{B}$ using $\mathrm{H}_{3} \mathrm{O}^{+}$ ions (Figure $3 \mathrm{~B}$ ) showed additional $\mathrm{m} / \mathrm{z}$ ratio response at 45 and 75 which were identified as dimethoxymethane and at $\mathrm{m} / \mathrm{z} 33\left(\mathrm{CH}_{5} \mathrm{O}^{+}\right)$identified as methanol [26]. The ions $\mathrm{NO}^{+}$confirmed the presence of $\mathrm{m} / \mathrm{z} 45$ and 75 . The ions $\mathrm{O}_{2}{ }^{+}$did not show additional compounds.
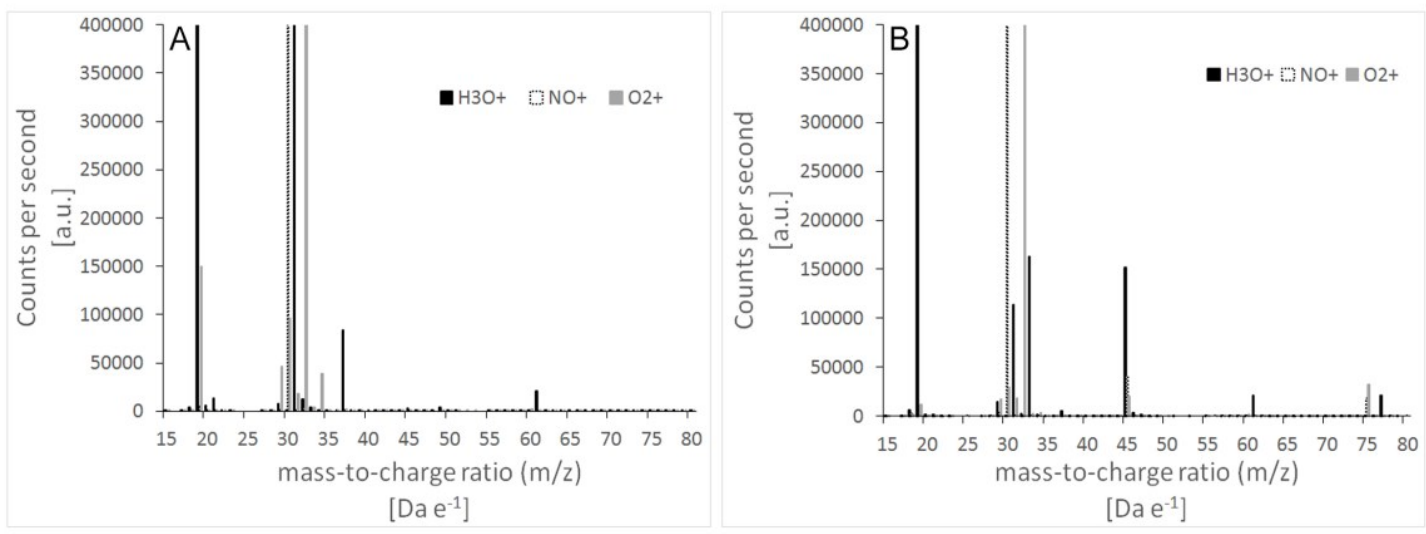

Figure 3. Full mass spectra from $15-80 \mathrm{Da} \mathrm{e}^{-1}$ using $\mathrm{H}_{3} \mathrm{O}^{+}, \mathrm{NO}^{+}$and $\mathrm{O}_{2}{ }^{+}$ions of two formaldehyde in hydrogen standard. Figure $\mathbf{4 A}$ presents the spectra of standard E, formaldehyde in hydrogen standard only 3 months old, stored at room temperature. Figure 4B presents the spectra of Standard B, formaldehyde in hydrogen standard almost 1.5 year old, stored at room temperature.

The technique was able to measure and estimate the content of three compounds in the formaldehyde in hydrogen gas standard: dimethoxymethane, methanol and formaldehyde (Table 2). The amount fractions were estimated based on the $k_{r}$ value from SIFT-MS database [22,26]. The results clearly showed the presence of methanol and dimethoxymethane at amount fractions equivalent or above formaldehyde in mixture $\mathrm{C}$ (the oldest one). On the other hand, only formaldehyde is observed in mixture D and E by SIFT-MS. This supports the difference in 
formaldehyde degradation observed between the cylinders.

Table 2. Quantification of formaldehyde, methanol and dimethoxymethane in three standards of formaldehyde in hydrogen. The amount fractions were estimated based on the $k_{r}$ value from SIFT-MS database [22,26].

\begin{tabular}{|c|c|c|c|c|}
\hline $\begin{array}{c}\text { Sample } \\
\text { number }\end{array}$ & $\begin{array}{c}\text { Number of day after } \\
\text { production }\end{array}$ & $\begin{array}{c}\text { Formaldehyde amount fraction } \\
{\left[\mu \mathrm{mol} \mathrm{mol}^{-1}\right]}\end{array}$ & $\begin{array}{c}\text { Methanol amount fraction } \\
{\left[\mu \mathrm{mol} \mathrm{mol}^{-1}\right]}\end{array}$ & $\begin{array}{c}\text { Dimethoxymethane amount fraction } \\
{\left[\mu \mathrm{mol} \mathrm{mol}^{-1}\right]}\end{array}$ \\
\hline $\mathrm{C}$ & 602 & 0.74 & 0.99 & 1.57 \\
\hline $\mathrm{D}$ & 344 & 4.63 & 0.02 & 0.05 \\
\hline $\mathrm{E}$ & 59 & 4.56 & 0.03 & 0.04 \\
\hline
\end{tabular}

The SIFT-MS techniques relies on reaction rate ' $k_{r}$ ' coefficient in the SIFT database. NPL formaldehyde in nitrogen gas standard was used to determine a reaction rate ' $k_{r, N 2}$ ' coefficient for formaldehyde in nitrogen. This new reaction rate ' $k_{r, N 2}$ ' coefficient $\left(k_{r, N 2}=1.16 \times 10^{-9} \mathrm{~cm}^{3} \mathrm{~s}^{-1}\right)$ was applied to quantify formaldehyde in hydrogen standard. The results of the different reaction rate are compared in Table 3.

Table 3. Quantification of formaldehyde amount fraction in three standard (C, D and E) using different reaction rate ' $k_{r}$ ' coefficient (Helium and nitrogen)

\begin{tabular}{|c|c|c|c|}
\hline $\begin{array}{l}\text { Sample } \\
\text { number }\end{array}$ & 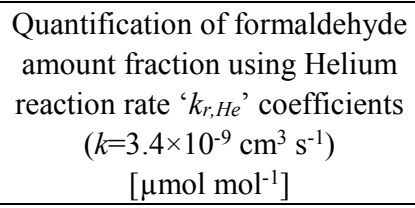 & 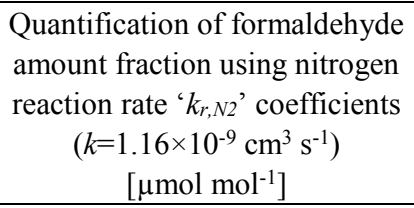 & $\begin{array}{l}\text { Quantification of formaldehyde amount } \\
\text { fraction using nitrogen reaction rate } \\
\text { ' } k_{r, N 2 c o r r '} \text { ' coefficient corrected for } \\
\text { stability }\left(k=1.35 \times 10^{-9} \mathrm{~cm}^{3} \mathrm{~s}^{-1}\right) \\
{\left[\mu \mathrm{mol} \mathrm{mol}{ }^{-1}\right]}\end{array}$ \\
\hline $\mathrm{C}$ & 0.74 & 2.17 & 1.86 \\
\hline $\mathrm{D}$ & 4.63 & 13.6 & 11.6 \\
\hline E & 4.56 & 13.4 & 11.5 \\
\hline
\end{tabular}

The quantification using the helium reaction and the nitrogen reaction rate provided completely different results. The use of the gravimetric value for formaldehyde in nitrogen required a slight correction to consider the potential degradation of formaldehyde over time using the decay rate of $1.6 \mathrm{nmol} \mathrm{day}^{-1}$ [18]. The standard $\mathrm{E}$ and $\mathrm{D}$ were quantified around 9.3 and $6.7 \mu \mathrm{mol} \mathrm{mol}^{-1}$. It clearly showed that none of the reaction rate coefficient are entirely accurate for quantifying formaldehyde in hydrogen. The use of helium reaction rate led to a relative underestimation of $28-51 \%$. The use of the corrected nitrogen reaction rate $\left(k_{r, N 2 c o r r}=1.35 \times 10^{-9} \mathrm{~cm}^{3} \mathrm{~s}^{-1}\right)$ led to a relative overestimation of $23-79 \%$.

Matrix effect should be considered regarding the use of reaction rate coefficient. Moreover a clear need of traceability and robust reaction rate determination in hydrogen matrix is recommended to allow SIFT-MS to provide reliable quantitative value in hydrogen matrix.

Gas chromatography with mass spectrometer

The GC-MS with preconcentrator was used to perform analysis of mixtures A, B and C several times during the first 6 months (see Figure 4). The presence of formaldehyde was demonstrated by the mass spectra (most abundant $\mathrm{m} / \mathrm{z}$ : 29). The presence of $\mathrm{CH}_{3} \mathrm{OH}$ and $\mathrm{CH}_{2}\left(\mathrm{OCH}_{3}\right)_{2}$ were identified at 3.3 and 4.9 min respectively by the mass spectra. The mass spectra of the peak at 3.3 min showed strong abundance of the following mass over charge ratio 31, 44 and $60 \mathrm{Da} \mathrm{e}^{-1}$ which matched methanol. The mass spectra of the peak at 4.9 min should strong abundance of the following mass over charge ratio 29,45 and $75 \mathrm{Da} \mathrm{e}^{-1}$ which matched dimethoxymethane. 

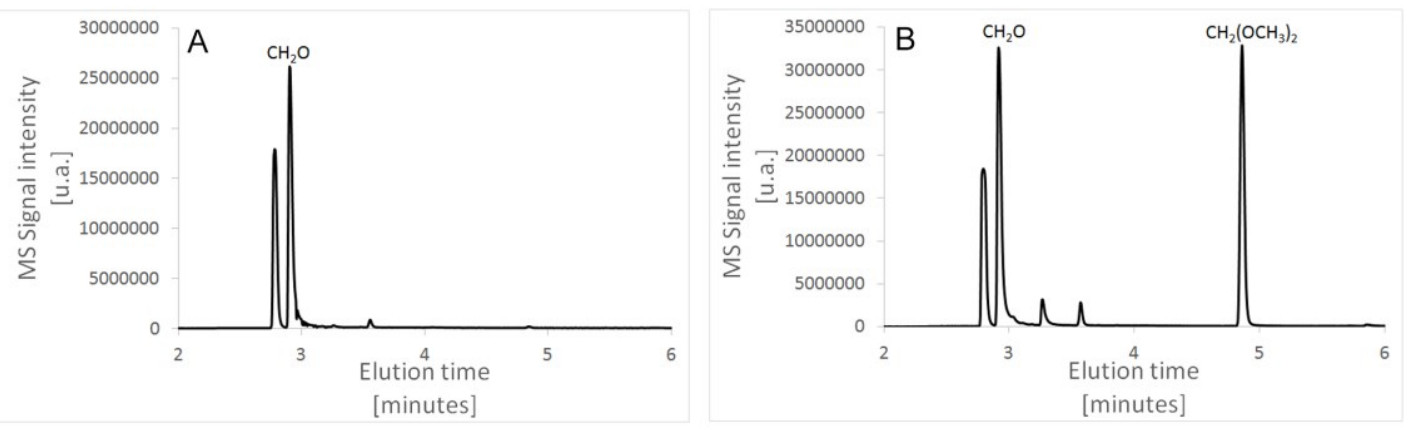

Figure 4. GC-MS with preconcentrator chromatograms for mixture B. The Figure 3A presents the chromatogram of mixture $\mathrm{B}$ after preparation (aged 1 day). Only one compound is present, $\mathrm{CH}_{2} \mathrm{O}$. The Figure $3 \mathrm{~B}$ presents the chromatogram of mixture $\mathrm{B}$ after 80 days of storage at room temperature. Three species were identified using the mass spectra: $\mathrm{CH}_{2} \mathrm{O}, \mathrm{CH}_{3} \mathrm{OH}$ and $\mathrm{CH}_{2}\left(\mathrm{OCH}_{3}\right)_{2}$

The results clearly demonstrate the increase in methanol and dimethoxymethane peak area and the decrease in formaldehyde. The evolution of the ratio between dimethoxymethane and methanol was difficult to follow as the experiments were performed at different times.

\section{By-products results}

The three techniques identified similar by-products of formaldehyde decomposition in hydrogen: methanol and dimethoxymethane. The ratio between methanol and dimethoxymethane was difficult to establish as no gas standards were available in a hydrogen matrix however they became the preponderant compounds in the formaldehyde in hydrogen mixture after several months.

For the purpose of hydrogen purity for fuel cell vehicles, the presence of carbon monoxide which has severe impact on the fuel cells and is a potential final by-product of formaldehyde decomposition, was investigated. Using the GC-PDHID instrument and gas standard of low amount fraction carbon monoxide in hydrogen, no carbon monoxide was observed above the limit of detection of our method $\left(0.1 \mu \mathrm{mol} \mathrm{mol}^{-1}\right)$, which represents less than $1 \%$ of the original formaldehyde amount fraction. For this reason, carbon monoxide was not considered a significant by-product of formaldehyde in hydrogen as prepared in this study.

\subsubsection{Thermodynamic stability of formaldehyde in hydrogen}

The reaction of formaldehyde with hydrogen gas to form methanol as observed above is the simple addition of the hydrogen (hydrogenation) across the $\mathrm{C}=\mathrm{O}$ double bond in formaldehyde (Equation 3). This reaction has been studied in the gas phase, as it is the final step in the formation of methanol between hydrogen and either carbon monoxide [19,20] or carbon dioxide [21]. These studies were performed at high concentrations of hydrogen, and carbon monoxide/carbon dioxide or formaldehyde; but the thermodynamics are equally valid for this dilute system.<smiles>O=CC1CC1</smiles>

Equation 3. Methanol formation

Direct measurements [20], thermodynamic calculations [27], and ab initio calculations [28] all give that gaseous methanol is approximately $88 \mathrm{~kJ} \mathrm{~mol}^{-1}$ more stable than a hydrogen/formaldehyde gas mixture (see Table 4). This large enthalpy change indicates that formaldehyde should convert to methanol at equilibrium. Using the data from NIST, as presented in Table 6, the Gibbs free energy for the formation of methanol from formaldehyde was calculated at various temperatures as listed in Table 5. The calculated $\Delta \mathrm{G}$ for the reaction is $-56 \mathrm{~kJ} \mathrm{~mol}^{-1}$ at room temperature $(298 \mathrm{~K})$ which is large and negative agreeing with the observed result that formaldehyde is unstable in hydrogen.

Table 4. Enthalpy and entropy change for the reactions

\begin{tabular}{|c|c|c|}
\hline & $\begin{array}{c}\Delta \mathrm{H}_{\mathrm{R}} \\
{\left[\mathrm{kJ} \mathrm{mol}^{-1}\right]}\end{array}$ & $\begin{array}{c}\Delta \mathrm{S}_{\mathrm{R}} \\
{\left[\mathrm{J} \mathrm{K}^{-1} \mathrm{~mol}^{-1}\right]}\end{array}$ \\
\hline $\mathrm{CH}_{2} \mathrm{O}+\mathrm{H}_{2} \Rightarrow \mathrm{CH}_{3} \mathrm{OH}($ Table 6$)$ & -89.1 & -109.73 \\
\hline $\mathrm{CH}_{2} \mathrm{O}+\mathrm{H}_{2} \Rightarrow \mathrm{CH}_{3} \mathrm{OH}[20]$ & -88 & -123 \\
\hline $\mathrm{CH}_{2} \mathrm{O}+\mathrm{H}_{2} \Rightarrow \mathrm{CH}_{3} \mathrm{OH}[28]$ & -84 & - \\
\hline & & -173.91 \\
\hline $\mathrm{CH}_{2} \mathrm{O}+2\left(\mathrm{CH}_{3} \mathrm{OH}\right) \Rightarrow \mathrm{CH}_{2}\left(\mathrm{OCH}_{3}\right)_{2}+\mathrm{H}_{2} \mathrm{O}$ & -63.93 & \\
\hline
\end{tabular}


The equilibrium constant $(K)$ was also calculated from the Gibbs free energy using Equation 4 (results in Table 5). Assuming that the concentration of formaldehyde and methanol is low $(<<1 \%)$ and the balance is hydrogen at 1 bar then we can assume that the partial pressure of hydrogen, $p_{\mathrm{H} 2}$, is approximately 1 . This simplifies

Equation 5 so that $K$ is effectively the equilibrium ratio of methanol to formaldehyde for these dilute systems.

$\Delta G=\Delta H-T \Delta S=-R T \ln K$

$K=\frac{p \mathrm{CH}_{3} \mathrm{OH}}{p \mathrm{H}_{2} \mathrm{pCH}_{2} \mathrm{O}} \approx \frac{p \mathrm{CH}_{3} \mathrm{OH}}{\text { ptot } p \mathrm{CH}_{2} \mathrm{O}}=\frac{x_{\mathrm{CH}_{3} \mathrm{OH}}}{x_{\mathrm{CH}_{2} \mathrm{O}}}$ if $p_{\mathrm{H} 2}=1 \mathrm{bar}$

Equation 4

Equation 5

This means that for a formaldehyde mixture at equilibrium, at room temperature and 1 bar, there should be $1 \times 10^{8}$ times less formaldehyde than methanol and there would still be about 200 times less formaldehyde at $300{ }^{\circ} \mathrm{C}$. So for any volume of gas stored at room temperature, practically all the formaldehyde would be converted to methanol at equilibrium, assuming low initial amount fraction of formaldehyde. Table 5 also shows that temperatures need to be in the order of $500{ }^{\circ} \mathrm{C}$ or higher to make formaldehyde stable in hydrogen at reasonable concentrations at one bar, which would not be feasible for storing gas standards. As the pressure in the cylinder increases $\left(p_{\mathrm{H} 2}\right)$ the amount of formaldehyde will decrease proportionally, so in the 100 bar test cylinders, there would be 100 times less formaldehyde at equilibrium. This is much lower than the measured amounts of formaldehyde, showing that the samples had not reached equilibrium over the course of the experiments.

Table 5. Gibbs free energy and Equilibrium constants for the hydrogenation of formaldehyde at various temperatures based on thermochemical data from Table 6 .

\begin{tabular}{|c|c|c|c|}
\hline $\begin{array}{c}\text { Temperature } \\
{[\mathrm{K}]}\end{array}$ & $\begin{array}{c}\text { Temperature } \\
{\left[{ }^{\circ} \mathrm{C}\right]}\end{array}$ & $\begin{array}{c}\Delta \mathrm{GR} \\
{\left[\mathrm{kJ} \mathrm{mol}^{-1}\right]}\end{array}$ & $\begin{array}{c}\text { Equilibrium constant } \\
{[\mathrm{K}]}\end{array}$ \\
\hline 298 & 25 & -56.4 & $7.70 \times 10^{9}$ \\
\hline 373 & 100 & -45.2 & $5.57 \times 10^{6}$ \\
\hline 573 & 300 & -23.3 & 245 \\
\hline 773 & 500 & -1.3 & 1.95 \\
\hline 973 & 700 & +20.6 & 0.11 \\
\hline
\end{tabular}

Thermodynamic stability: Dimethoxymethane formation

The other species observed in the gas mixtures was Dimethoxymethane (DMM, Methylal) which forms from the reaction of two methanol molecules with one formaldehyde molecule as shown in Equation 6 . As with methanol formation, the formation of DMM (and water) is exothermic $\left(64 \mathrm{~kJ} \mathrm{~mol}^{-1}\right)$, with equilibrium position favouring DMM formation up to $367 \mathrm{~K}\left(94{ }^{\circ} \mathrm{C}\right)$ (data from Table 6). This equation suggests there should be water formation as well that was observed after 1 year storage. Water amount fraction was measured using cavity ring down spectrometer after 1 year in mixture B and C. The amount fraction in both mixture was between $2.0-2.4 \mu \mathrm{mol}$ $\mathrm{mol}^{-1}$ which is coherent with the equation.

The thermodynamics clearly agrees with the observed data that a mixture of dilute formaldehyde in hydrogen is unstable when stored below $300{ }^{\circ} \mathrm{C}$, and will completely convert to methanol or methanol and DMM at equilibrium. The timescale of this process is clearly on the scales of weeks to months, but it is useful to look at the kinetics to understand the process better and to understand why the species formed were different in the two samples.<smiles>COCOC=CC#CCOC=[18CH]C=O</smiles>

Equation 6

Methanol formation Kinetics

$A b$ initio studies of this system [28,29] provide an estimate of the activation barrier for the conversion of formaldehyde to methanol, and which can be used to give an indication of its reaction kinetics. The activation energy barrier $\left(\Delta E_{a}\right)$ for the gas phase reaction of formaldehyde and hydrogen is estimated in the range between $250 \mathrm{~kJ} \mathrm{~mol}^{-1}$ [29] and $290 \mathrm{~kJ} \mathrm{~mol}^{-1}$ [28]. This is a very large energy barrier and will result in very slow kinetics at 
low temperatures. Assuming Arrhenius kinetics, with reaction rate constant $k_{A}$ defined as $k_{A}=A e^{-\Delta E_{a} / R T}$, and with the pre-exponential factor $(A)$ of $10^{-11} \mathrm{~cm}^{3} \mathrm{~s}^{-1}$ and $\Delta E_{a}=292 \mathrm{~kJ} \mathrm{~mol}^{-1}$ from Jasper et al [28], the rate formation of methanol at $25{ }^{\circ} \mathrm{C}$ would be approximately $4.2 \times 10^{-40} \mathrm{~Pa} \mathrm{~s}^{-1}$. This is extremely slow, and implies that formaldehyde in the mixture would be kinetically stable with respect to the gas-phase reaction with hydrogen for considerable periods of time at ambient temperature.

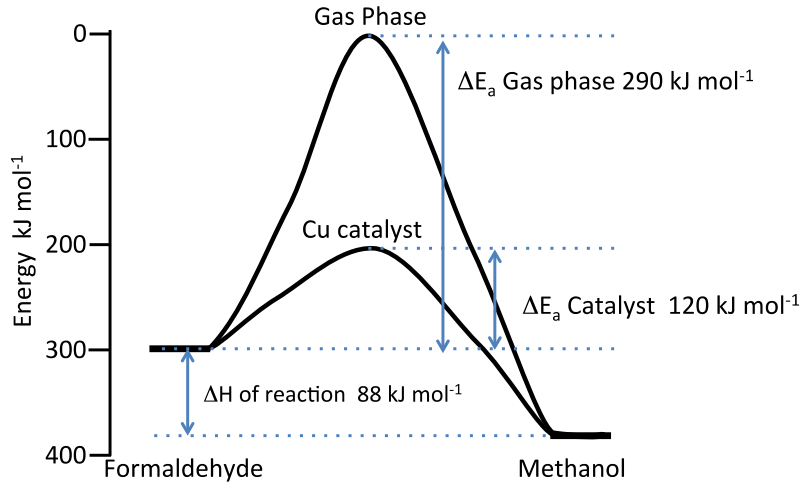

Figure 5 Reaction pathway based on data from Jasper at al. [29] and Studt et al. [33].

However formaldehyde adsorbs strongly onto surfaces (one of the reasons why it is a poison to fuel cell catalysts [30]). This adsorption is thought to facilitate the hydrogenation reaction. There have been several studies on the kinetics of hydrogenation on various catalytic surfaces such as platinum, nickel, palladium, ruthenium, cobalt, rhodium, osmium, iridium, and iron [31-32], copper [33], iron carbides [34], copper-zinc [35], etc. All surfaces show significant catalytic activity with the activation barrier dropping, for example, to $107 \mathrm{~kJ} \mathrm{~mol}^{-1}$ on copper [33] or to $125 \mathrm{~kJ} \mathrm{~mol}^{-1}$ on nickel(111) [32]. The various energy levels are depicted in Figure 5. This much lower barrier, along with the enhanced surface concentration resulting from formaldehyde adsorption, would give a significant turnover of formaldehyde in a reasonable at even room temperature. With the low levels of formaldehyde and the still lengthy time scales observed above, it would only require a small amount of catalyst in a cylinder, such as exposed iron or nickel inclusions in the stainless steel or any metal fragments/dust on the cylinder internal surface to produce the observed reaction rate.

\section{DMM kinetics}

The mechanism to form DMM is a two-step process with the reaction of one formaldehyde with one methanol to form the hemicetal methoxymethanol, (Equation 7), then the addition of another methanol to the hemiacetal to form the stable acetal, DMM, (Equation 8) [36].

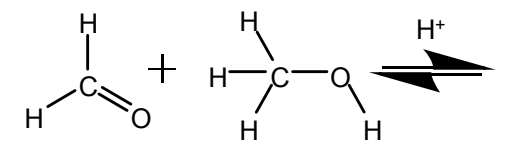<smiles>COCO</smiles>
Equation 7

$\mathrm{CH}_{2} \mathrm{O}+\mathrm{CH}_{3} \mathrm{OH} \Leftrightarrow \mathrm{CH}_{2} \mathrm{OH}-\mathrm{OCH}_{3}$<smiles>COCO</smiles><smiles>COCOC</smiles>

$\mathrm{CH}_{2} \mathrm{OH}-\mathrm{OCH}_{3}+\mathrm{CH}_{3} \mathrm{OH} \Leftrightarrow \mathrm{H}_{3} \mathrm{CO}-\mathrm{CH}_{2}-\mathrm{OCH}_{3}+\mathrm{H}_{2} \mathrm{O}$

Both these steps need an external source of $\mathrm{H}^{+}$to occur [37] therefore this reaction cannot happen in a purely gaseous system, unlike methanol formation. It requires either an acidic solution or a solid acid catalyst to occur. However any catalyst that could adsorb formaldehyde and aid its conversion to methanol, is also probably capable of catalysing this reaction. The presence of DMM in only one cylinder suggests that it has a slightly different catalytic impurity than the other cylinder. This also means the amount of the two species will depend on the type and amount of catalyst present.

The thermodynamic data agrees with the observed results, that the dilute formaldehyde in hydrogen will hydrogenate to form methanol and/or dimethoxymethane. However both these species require a catalyst to form at the rate observed. The rate of conversion and the species formed will entirely depend on the adventitious materials in the cylinder that act as the catalyst, which will vary from cylinder to cylinder as seen between similar cylinders $\mathrm{B}$ and $\mathrm{C}$ and later cylinder $\mathrm{D}$. 
Table 6. Thermochemical data of species, data from NIST [27]

\begin{tabular}{|c|c|c|}
\hline & $\begin{array}{c}\Delta \mathrm{H}_{\mathrm{f}} \\
{\left[\mathrm{kJ} \mathrm{mol}^{-1}\right]}\end{array}$ & $\begin{array}{c}\mathrm{S} \\
{\left[\mathrm{J} \mathrm{K}^{-1} \mathrm{~mol}^{-1}\right]}\end{array}$ \\
\hline $\mathrm{CH}_{3} \mathrm{OH}$ & -205 & 239.9 \\
\hline $\mathrm{CH}_{2} \mathrm{O}$ & -115.9 & 218.95 \\
\hline $\mathrm{H}_{2}$ & 0 & 130.68 \\
\hline $\mathrm{CH}_{2}\left(\mathrm{OCH}_{3}\right)_{2}$ & -348 & 336 \\
\hline $\mathrm{H}_{2} \mathrm{O}$ & -241.83 & 188.84 \\
\hline
\end{tabular}

Table 7. Kinetic related Data used for the calculation

\begin{tabular}{|c|c|c|}
\hline Variable & Initial unit & SI unit \\
\hline Partial Pressure $\mathrm{H}_{2}$ & $100 \mathrm{Bar}$ & $1 \times 10^{7} \mathrm{~Pa}$ \\
\hline Partial Pressure $\mathrm{CH}_{2} \mathrm{O}$ & $1 \mathrm{ppm}$ & $10 \mathrm{~Pa}$ \\
\hline Pre-exponential A $[28]$ & $2.285 \times 10^{-11} \mathrm{~cm}^{3} \mathrm{~s}^{-1}$ & $5.55 \times 10^{3} \mathrm{~Pa}^{-1} \mathrm{~s}^{-1}$ \\
\hline$\Delta \mathrm{E}_{\mathrm{A}}$ Gas phase [28] & $35080 \mathrm{~K}$ & $292 \mathrm{~kJ} \mathrm{~mol}^{-1}$ \\
\hline$\Delta \mathrm{E}_{\mathrm{A}} \mathrm{Cu}$ surface & $1.11 \mathrm{eV}$ & $107 \mathrm{~kJ} \mathrm{~mol}^{-1}$ \\
\hline
\end{tabular}

\subsection{Recommendations to the hydrogen industry}

This study has demonstrated that formaldehyde is unstable in hydrogen. The observed degradation kinetics is quicker than that calculated from the thermodynamic data and may be linked to a catalytic conversion. Reactive surfaces in the cylinder and, by extension, the piping material used in the hydrogen industry may act as catalyst for the hydrogenation of formaldehyde. Therefore the absence of formaldehyde in a hydrogen sample may be linked to similar reactivity. If that was the case, the by-products observed in this study (methanol and dimethoxymethane) may be present in a real hydrogen sample. During this study, a real sample of hydrogen from the electrolysis process was analysed for methanol and dimethoxymethane by GC-MS with preconcentrator, which was the most sensitive technique available. No formaldehyde, methanol or dimethoxymethane were observed; which was expected as the electrolysis process would never form formaldehyde during operation. Further studies are required to investigate the presence of the formaldehyde by-products in real samples from the steam-methane reforming process, which are more likely to contain formaldehyde impurities. Moreover, as the formaldehyde would immediately convert to methanol and dimethoxymethane by-products, the impact of these impurities to fuel cells should be studied as they could contribute to degradation.

\section{Summary}

NPL successfully prepared gas standards of formaldehyde in hydrogen. The mixtures prepared were stable for 8 weeks within a $10 \%$ uncertainty $(k=1)$, mainly due to formaldehyde degradation. The main degradation products were identified as methanol and dimethoxymethane by means of FTIR, GC-MS and SIFT-MS. Thermodynamic calculations confirmed that formaldehyde is unstable in hydrogen and reacts to form methanol, which can go on to form dimethoxymethane (as well as other possible compounds). These reactions however do need some form of catalyst to occur at reasonable rates at room temperature (which could be cylinder walls or the metallic inner surface of the hydrogen refueling station). The catalytic nature of formaldehyde instability indicates that the cylinder or vessel used is crucial to determine the mixture stability. For the purpose of this study, aluminum cylinders with a surface passivation treatment (SPECTRA-SEAL ${ }^{\circledR}$, BOC, UK) were used as the current state-ofthe-art. Primary Reference Material of formaldehyde in hydrogen can indeed be prepared bearing in mind that a short shelf life should be provided ( 8 weeks for stability uncertainty of $10 \% ; k=1$ ). The mixture uncertainty will be strongly linked to the stability uncertainty and the validity of the certified value. Further studies are required to determine if new cylinder types or surface passivation techniques can reduce the catalytic degradation of formaldehyde.

The study has also directly called into question whether formaldehyde is present in hydrogen produced in industrial processes (electrolysis, steam methane reforming or chlor-alkali) as the gas lines used may provide sufficient catalytic surface area to ensure transformation of formaldehyde into methanol or dimethoxymethane (even if formaldehyde would have been present in the first place). The presence of methanol or dimethoxymethane may therefore be a marker for formaldehyde impurities. This study did not observe any degradation of formaldehyde into carbon monoxide providing that this is unlikely to happen during hydrogen production.

Further studies are required to investigate other preparation methods of mixtures of formaldehyde in hydrogen (i.e. dynamics methods) as well as to establish the presence of formaldehyde by-products in real samples of hydrogen coming from hydrogen refueling stations. If these findings prove that there is very little risk of formaldehyde being present in hydrogen provided to fuel cell vehicles, it would be sound evidence for removing this impurity from the ISO 14687 specifications. 


\section{Acknowledgements}

'This work was supported by Innovate UK [Project No: 101830]

[1] UK H2 Mobility (2013) UK H2 Mobility - Phase 1 Results, http://www.ukh2mobility.co.uk/wpcontent/uploads/2013/08/UKH2-Mobility-Phase-1-Results-April-2013.pdf; accessed on 30/08/2017.

[2] ISO 14687-2:2012 (2012) Hydrogen fuel—product specification— part 2: proton exchange membrane (PEM) fuel cell applications for road vehicles. International Organization for Standardization, Geneva, Switzerland

[3] Narusawa K., Hayashida M., Kamiya Y., Roppongi H., Kurashima D., Wakabayashi K. (2003) Deterioration in fuel cell performance resulting from hydrogen fuel containing impurities: poisoning effects by $\mathrm{CO}, \mathrm{CH} 4, \mathrm{HCHO}$ and $\mathrm{HCOOH}$. JSAE Review, 24 (1), 41-46

[4] Murugan A., Brown A. S. (2015) Review of purity analysis methods for performing quality assurance of fuel cell hydrogen. International Journal of Hydrogen Energy, 40(11), 4219-4233.

[5] Hoelbling S. (2014) Atmospheric Measurements of Formaldehyde in Rural Western North Carolina. J Stud Res Environ Sci, 4,44-53

[6] ASTM D7892-15 Standard Test Method for Determination of Total Organic Halides, Total Non-Methane Hydrocarbons, and Formaldehyde in Hydrogen Fuel by Gas Chromatography/Mass Spectrometry, ASTM International, West Conshohocken, PA, 2015, https://doi.org/10.1520/D7892-15

[7] Luong J., Sieben L., Fairhurst M., De Zeeuw, J. (1996), Determination of low levels of formaldehyde and acetaldehyde by gas chromatography/flame ionization detection with a nickel catalyst. J. High Resol. Chromatogr, $19,591-594$.

[8] ASTM D7653-10 Standard Test Method for Determination of Trace Gaseous Contaminants in Hydrogen Fuel by Fourier Transform Infrared (FTIR) Spectroscopy, ASTM International, West Conshohocken, PA, 2010, https://doi.org/10.1520/D7653-10

[9] Lawson D.R., Biermann H.W., Tuazon E.C., Winer A.M., Mackay G.I., Schiff H.I., Kok G.L., Dasgupta P.K., Fung K. (1990) Formaldehyde Measurement Methods Evaluation and Ambient Concentrations During the Carbonaceous Species Methods Comparison Study. Aerosol Sci Technol, 12, 64-76

[10] Buzcu Guven B, E.P. Olaguer EP (2011) Ambient formaldehyde source attribution in Houston during TexAQS II and TRAMP, Atmos. Env., 45, 4272

[11] Fried A., Wang Y., Cantrell C., Wert B., Walega J., Ridley B., Atlas E., Shetter R., Lefer B., Coffey M.T., Hannigan J., Blake D., Blake N., Meinardi S., Talbot B., Dibb J., Sheuer E., Wingenter O., Snow J., Heikes B., Ehhalt D. (2003) Tunable diode laser measurements of formaldehyde during the TOPSE 2000 study: Distributions, trends, and model comparisons. J Geophys Res, 108, 8365

[12] Warneke C., Veres P., Holloway J.S., Stutz J., Tsai C., Alvarez S., Rappernglueck B., Fehsenfeld F.C., Graus M., Gilman J.B., de Gouw J.A. (2011) Airborne formaldehyde measurements using PTR-MS: calibration, humidity dependence, inter-comparison and initial results. Atmos Meas Tech, 4, 2345-2358

[13] Španěl P., Smith D. (2008) Quantification of trace levels of the potential cancer biomarkers formaldehyde, acetaldehyde and propanol in breath by SIFT-MS. J. Breath Res. 2, 046003

[14] Hak C., Pundt I., Trick S., Kern C., Platt U., Dommen J., Ordonez C., Pre'vot A.S.H., Junkermann W., Astorga-Llorens C., Larsen B.R., Mellqvist J., Strandberg S., Yu Y., Galle B., Kleffmann J., Lorzer J., Braathen G.O., Volkamer R. (2005) Intercomparison of four different in-situ techniques for ambient formaldehyde measurements in urban air, Atmos Chem Phys, 5, 2881-2900

[15] Wisthaler A., Apel E.C., Bossmeyer J., Hansel A., Junkermann J.W., Koppmann R., Meier R., Muller K., Solomon S.J., Steinbrecher R., Tillmann R., Brauers T. (2008) Technical Note: Intercomparisonof formaldehyde measurements at the atmosphere simulation chamber SAPHIR. Atmos Chem Phys, 8, 2189-2200

[16] Panda N., Kim M., Aoki N., Zhou Z., Shimosaka T., Kim Y., Lee S., Kim D. (2016) Validation of primary formaldehyde gas standards prepared by dynamic thermogravimetry through a tri-national comparison of gaseous formaldehyde amount fraction. Accred Qual Assur, DOI 10.1007/s00769-016-1219-7 
[17] Chu P.M., Thorn W.J., Sams R.L., Guenther F.R. (1997) On-Demand Generation of a Formaldehyde-in-Air Standard. J Res Natl Inst Stand Technol, 102, 559-568

[18] Brewer P.J., di Meane E.A., Vargha G. M., Brown R.J.C., Milton M.J.T. (2013) Gaseous reference standards of formaldehyde from trioxane. Talanta, 108, 83-87.

[19] Neurock M. (1999) First-principles analysis of the hydrogenation of carbon monoxide over palladium. Topics in Catalysis, 9, 135-152

[20] Newton R.H., Dodge B.F. (1933) The Equilibrium between Carbon Monoxide, Hydrogen, Formaldehyde and Methanol. The Reactions $\mathrm{CO}+\mathrm{H} 2$-> HCOH and $\mathrm{H} 2+\mathrm{HCOH}->\mathrm{CH} 3 \mathrm{OH}$. J. Am. Chem. Soc., 55(12), 47474759

[21] Tao X., Wang J., Li Z., Ye Q. (2013) Theoretical study on the reaction mechanism of CO2 hydrogenation to methanol Computational and Theoretical Chemistry, 1023, 59-64

[22] Španěl D., Ji Y., Smith D. (1997) SIFT studies of the reactions of H3O+, NO+ and O2+ with a series of aldehydes and ketones. Int. J. Mass Spectrom. Ion Proc., 165/166, 25-37

[23] Linsinger T.P.J., Pauwels J., Lamberty A., Schimmel H., van der Veen A.M.H., Siekmann L. (2001) Estimating the Uncertainty of Stability for Matrix CRMs, Fres. J. Anal. Chem., 370, 183-188.

[24] ISO Guide 34 (2009) General requirements for the competence of reference material producers. International Organization for Standardization, Geneva, Switzerland

[25] Sharpe S.W., Johnson T.J., Sams R.L., Chu P.M., Rhoderick G.C., Johnson P.A. (2004) Gas-Phase Databases for Quantitative Infrared Spectroscopy, Appl. Spectrosc. 58, 1452-1461

[26] Španěl P., Smith D. (1997) SIFT studies of the reactions of H3O+, NO+ and O2+ with a series of alcohols. Int. J. Mass Spectrom. Ion Processes, 167-168, 375-388.

[27] NIST-JANAF Themochemical Tables, Fourth Edition, M.W. Chase Jr., J. Phys. Chem. Ref. Data, Monograph 9, 1998, 1-1951.

[28] Jasper A.W., Klippenstein S.J., Harding L.B., Ruscic B. (2007) Kinetics of the Reaction of Methyl Radical with Hydroxyl Radical and Methanol Decomposition. J. Phys. Chem. A, 111, 3932-3950

[29] Ing W-C, Sheng C.Y., Bozzelli J. W. (2003) Development of a detailed high-pressure reaction model for methane/methanol mixtures under pyrolytic and oxidative conditions and comparison with experimental data. Fuel Processing Technology, 83, 111-145

[30] Narusawa K., Hayashida M., Kamiya Y., Roppongi H., Kurashima D., Wakabayashi K. (2003) Deterioration in fuel cell performance resulting from hydrogen fuel containing impurities: poisoning effects by $\mathrm{CO}, \mathrm{CH} 4$, HCHO and HCOOH. JSAE Review, 24(1), 41-46

[31] Aika K., Sekiya H., Ozaki A. (1983) Selectivities of Group VIII Metals for the Hydrogenation of Formaldehyde and the Effect of Support and Promoter. Chemistry Letters. 301 - 304

[32] Remediakis I. N., Abild-Pedersen F., JNørskov . K. (2004) DFT Study of Formaldehyde and Methanol Synthesis from $\mathrm{CO}$ and $\mathrm{H}_{2}$ on $\mathrm{Ni}(111)$. J. Phys. Chem. B, 108, 14535-14540

[33] Studt F., Abild-Pedersen F., Wu Q., Jensen A. D., Temel B., Grunwaldt J-D, Nørskova J. K. (2012) CO Hydrogenation to methanol on Cu-Ni Catalysts: Theory and Experiment. Journal of Catalysis, 293, 51-60

[34] Olus Ozbek M., Niemantsverdriet J.W. (2015) Methane, formaldehyde and methanol formation pathways from carbon monoxide and hydrogen on the (001) surface of the iron carbide v-Fe5C2. Journal of Catalysis, 325, 9-18

[35] Jadhav S. G., Vaidya P. D., Bhanage B. M., Joshi J. B. (2014) Catalytic carbon dioxide hydrogenation to methanol: A review of recent studies. Chemical Engineering Research And Design, 92, 2557-2567

[36] Damiri S., Pouretedal H. R., Bakhshi O. (2016) An extreme vertices mixture design approach to the optimization of methylal production process using p-toluenesulfonic acid as catalyst. Chemical Engineering Research and Design, 112, 155-162

[37] Nikonovaa O. A., Capronb M., Fangb G., Fayeb J., Mamedeb A-S, Jalowiecki-Duhamel L., Dumeignil F., Seisenbaeva G. A. (2011) Novel approach to rhenium oxide catalysts for selective oxidation of methanol to DMM. Journal of Catalysis 279(2), 310-318 